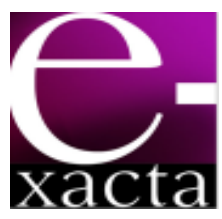

ISSN: 1984-3151

\title{
Automatização do Controle do PCI E MELhoRIA do CONTROLE DA RELAÇÃO ESTEQUIOMÉTRICA DE UM FORNO DE COMBUSTÃO A GÁS
}

\section{AUTOMATION OF LHV CONTROL AND IMPROVED OF STOICHIOMETRIC CONTROL OF A GAS COMBUStION FURNACE}

\author{
Wanderson Miliano de Jesus; Wagner José Rodrigues \\ Centro Universitário de Belo Horizonte, Belo Horizonte, MG \\ wanderson.miliano@vmtubes.com.br; rodrigueswjose@gmail.com
}

Recebido em: 30/05/2011 - Aprovado em: 30/06/2011 - Disponibilizado em: 24/07/2011

\begin{abstract}
RESUMO: Com o objetivo de reduzir o consumo de gás natural e melhorar a qualidade do material com a redução da geração de carepa de um forno de combustão a gás, foi recalculada a curva de relação estequiométrica e implementado um programa no PLC para automatização do controle do $\mathrm{PCl}$, trabalhando em cascata com o controle de ciclo dos queimadores "ON/OFF". Pelos testes efetuados a expectativa é de que seja superada a estimativa de redução do consumo de gás natural, mas para operação em regime contínuo é necessário avaliar a demanda disponível de gás de alto forno. Este projeto poderá ser expandido para outros fornos que utilizam o gás misto como fonte principal de energia para a combustão.

PalavRAS-CHAVE: Gás Natural. Estequiométrica. Automatização. Controle do PCI.
\end{abstract}

ABSTRACT: Aiming to reduce natural gas consumption and to improve the quality of the material reducing tube's scale generation of a gas combustion furnace, the stoichiometric curve was recalculated and was implemented an automation program for LHV control on the PLC, working in cascade with the "ON / OFF" burner's cycle control. In tests performed, the expectation is to exceed estimated reduction in consumption of natural gas, but in continuous operation is necessary to evaluate the available demand for blast furnace gas. This project could be expanded to other furnaces using gas mixture as the main energy source for combustion.

KEYWORDS: Natural Gas. Stoichiometric. Automation. LHV Control.

\section{INTRODUÇÃo}

Atualmente foram estabelecidas normas ambientais rigorosas para as indústrias devido à crescente preocupação ecológica mundial. Para otimizar a eficiência térmica dos fornos industriais é necessário minimizar o excesso de ar, assegurando ao mesmo tempo o cumprimento das normas ambientais.

O excesso de ar controla o volume, temperatura e entalpia dos produtos da combustão, portanto é fator determinante da eficiência da combustão. Um grande excesso de ar reduz a eficiência térmica do forno, mas por outro lado, um baixo excesso de ar pode resultar em uma combustão incompleta e risco de explosão.
O Gás Natural (GN) utilizado na combustão do forno possui um custo elevado e em termos de poluição atmosférica, destacam-se as emissões de óxidos de nitrogênio (NOx), entre os quais o dióxido de nitrogênio (NO2) e o óxido nitroso (N2O), que são formados pela combinação do nitrogênio com o oxigênio, além da emissão de monóxido de carbono (CO).

O estudo foi realizado com o objetivo de reduzir o consumo de gás natural do forno em torno de $10 \%$ através da automatização do controle do poder calorífico inferior $(\mathrm{PCl})$ e melhorar a qualidade do material com a redução de geração de carepa devido 
excesso de oxigênio na atmosfera interna do forno. Desta forma têm-se os seguintes objetivos específicos:

- Atualizar a curva de relação estequiométrica do forno;

- Implementar um programa no programador lógico programável (PLC) para automatização do controle do PCl;

- Implementar um controle dos queimadores "ON/OFF" em cascata com o controle do PCI.

O NO2 é um dos principais componentes do chamado "smog", ou seja, uma mistura de fumaça (contendo vários poluentes) e de nevoeiro, que, sob determinadas condições atmosféricas, se forma sobre os grandes centros urbanos e industriais, com efeitos negativos sobre a vegetação e a saúde humana, principalmente quando combinado com outros gases, como o dióxido de enxofre (SO2). O N2O é um dos gases causadores do chamado efeito estufa e também contribui para a redução da camada de ozônio. O CO também é prejudicial à saúde humana, onde os principais problemas são sentidos no sistema cardiovascular e nervoso especialmente em indivíduos com problemas coronários. Em concentrações mais elevadas pode causar tonturas, dores de cabeça e fadiga.

Portanto não apenas pelos ganhos financeiros, a redução do consumo de $\mathrm{GN}$ e o controle do excesso de oxigênio de um forno de combustão gás são de extrema importância para garantia da preservação do meio ambiente.

\section{RefERENCIAL TEÓRICO}

Em muitos processos químicos os fatores que geram falhas em filtro de mangas são originários de falta de controle térmico efetivo em fornos industriais, principalmente nos teores de oxigênio (Figura 1).

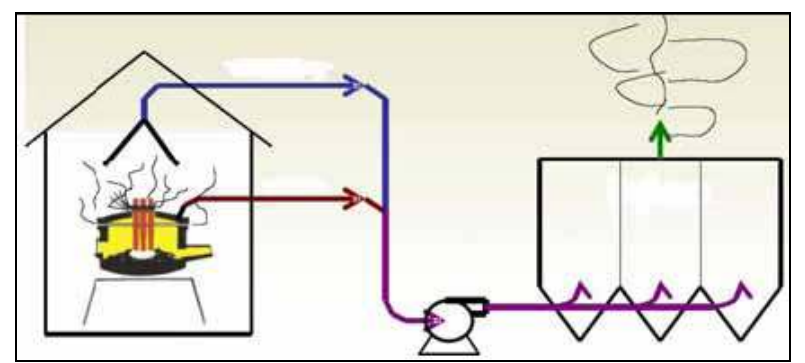

FIGURA 1 - Liberação de gases de forno elétrico para filtro de mangas

Fonte: Pinheiro; Valle, 1995.

Precisa-se considerar a influência do excesso de ar na eficiência térmica e no nível de emissão de poluentes (CO, SOx, NOx) dos fornos, a inter-relação existente entre estes fatores e os passos necessários para a otimização do coeficiente de excesso de ar. O controle da poluição por particulados e o controle do rendimento térmico de fornalhas são, normalmente, realizados de forma independente pelos respectivos operadores (Figura 2) (PINHEIRO; VALLE, 1995).

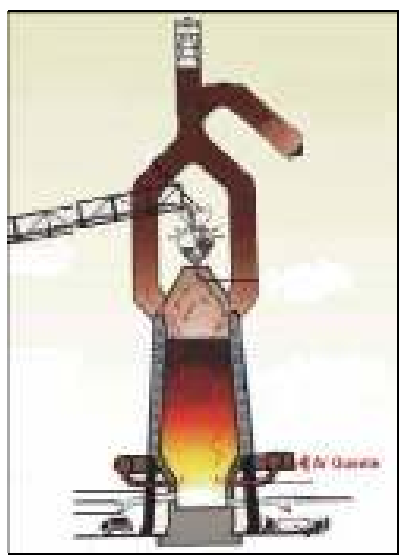

FIGURA 2 - Entrada de ar quente em alto forno

FONTE: Pinheiro; Valle, 1995.

Os mesmos autores afirmam que para realizar a combustão é necessária uma quantidade de ar estequiométrica, chamada ar teórico. Entretanto, para assegurar a combustão completa é necessário um "excesso de ar" para manter um teor suficiente de 
oxigênio até o final da chama, para superar as deficiências de mistura do queimador. Os valores referentes ao excesso de ar, conforme o combustível e fornalha são mostrados na Tabela 1.

\section{Tabela 1}

\section{VALORES USUAIS: COEFICIENTE DE EXCESSO DE AR A}

\begin{tabular}{|l|l|c|}
\hline \multicolumn{1}{|c|}{ Combustivel } & Tipo de Fornalha ou Queimador & $\boldsymbol{\alpha}$ \\
\hline Carvão Pulverizado & Aquatubular completa & $1,15-1,20$ \\
& Aquatubular parcial fundo seco & $1,15-1,40$ \\
\hline Carvão Britado & Fornalha Ciclone & $1,10-1,15$ \\
\hline Carvão & Grelha fixa & $1,30-1,60$ \\
& Grelha vibratória & $1,30-1,60$ \\
& Grelha rotativa & $1,15-1,50$ \\
& Grelha fixa alimentação por baixo & $1,20-1,50$ \\
\hline Óleo Combustível & Queimadores de óleo tipo registro & $1,05-1,15$ \\
& Queimadores multicombustível & $1,05-1,20$ \\
\hline Resíduo Ácido & Queimadores chama plana a vapor & $1,10-1,15$ \\
\hline Gás Natural & Queimadores tipo registro & $1,05-1,10$ \\
\hline Gás Coqueria & Queimadores multicombustível & $1,07-1,12$ \\
\hline Gás Alto-forno & Queimadores de bocal intertubos & $1,15-1,18$ \\
\hline Madeira & Grelha & $1,20-1,25$ \\
\hline Bagaço & Todas as fornalhas & $1,25-1,35$ \\
\hline Licor Negro & Fornalhas recuperação Kraft e Soda & $1,05-1,07$ \\
\hline
\end{tabular}

FONTE: Pinheiro; Valle, 1995.

Um grande excesso de ar é indesejável, por que diminui a temperatura da chama e aumenta as perdas de calor devido à entalpia dos gases efluentes, reduzindo a eficiência térmica, além de diminuir o comprimento da chama. Por outro lado, um baixo excesso de ar pode resultar em uma combustão incompleta e na formação de $\mathrm{CO}$ gerar fuligem e fumaça, além de possibilitar a acumulação de combustível não queimado, causando risco de explosão.

O poder calorífico define-se como a quantidade de energia na forma de calor liberada pela combustão de uma unidade de massa da madeira, ou ainda, é a energia efetivamente disponível por unidade de massa de combustível após deduzir as perdas com a evaporação da água (JARA, 1989).

No Sistema Internacional o poder calorífico é expresso em joules por grama ou quilojoules por quilo, mas pode ser expresso em calorias por grama ou quilocalorias por quilograma. Ele divide-se em superior e inferior. O poder calorífico superior é aquele em que a combustão se efetua a volume constante, no qual a água formada durante a combustão é condensada e o calor que é derivado desta condensação é recuperado (BRIANE; DOAT, 1985).

O estudo se caracteriza como uma pesquisa experimental do tipo estudo de caso, pois, como afirma Gil (2002), pode-se definir pesquisa experimental como o procedimento racional e sistemático que tem como objetivo proporcionar respostas aos problemas que são propostos. A pesquisa é desenvolvida mediante o concurso dos conhecimentos disponíveis e a utilização cuidadosa de métodos, técnicas e outros procedimentos científicos e um estudo de caso como sendo um estudo profundo e exaustivo de um ou poucos objetos, de maneira que permita seu amplo e detalhado conhecimento. $\mathrm{O}$ autor diz que essa modalidade de pesquisa é amplamente utilizada nas ciências sociais e biomédicas e que seus resultados, principalmente na área de biomédicas, são apresentados em aberto, ou seja, na condição de hipóteses, não de conclusões.

O procedimento metodológico adotado para o desenvolvimento da pesquisa consistiu em realizar um levantamento bibliográfico sobre o tema com a finalidade de nivelar o conhecimento do pesquisador $\mathrm{e}$ obter dados para a discussão dos resultados.

Os passos seguintes consistiram em levantar junto a Gerência de Energia da Vallourec \& Mannesmann do Brasil (VMB) a curva de relação estequiométrica elaborada em 1998 que foi utilizada para determinar a pressão do ar de combustão em relação ao ajuste do $\mathrm{PCl}$, garantindo um excesso de oxigênio na atmosfera do forno de $2 \%$. Posteriormente foi verificada a capacidade de ajuste do $\mathrm{PCl}$ para as dimensões atuais das tubulações de gás de alto forno (GAF) e gás natural e, com base nestes dados, foi atualizada a curva de relação estequiométrica do forno.

A partir da curva de relação estequiométrica modificada partiu-se para a implementação de um 
programa no PLC para automatização do controle do $\mathrm{PCl}$, levando-se sempre em consideração a priorização do consumo de gás de alto forno em relação ao gás natural.

Em conjunto à automatização do controle do $\mathrm{PCl}$ foi implementado um programa para garantir que os queimadores "ON/OFF" trabalhassem em cascata com o controle do $\mathrm{PCl}$, ou seja, tendo o objetivo de priorizar sempre o maior número de queimadores possiveis acesos para posteriormente trabalhar com enriquecimento do gás de alto forno com o gás natural.

\section{Resultados e Discussão}

Este projeto foi desenvolvido em um forno de reaquecimento da Laminação Contínua de Tubos da VMB, tendo como produto final tubos de aço sem costura laminados a quente. Este é um forno de combustão a gás com a filosofia conhecida como "ON/OFF" ou forno digital, onde o controle se dá através da ciclagem de queimadores ligados $e$ desligados. Na Figura 3 pode-se verificar a representação "imaginária" das várias zonas de aquecimento, ele possui 12 zonas de controle sem barreira física entre elas, sendo 6 de aquecimento na entrada, além de 6 de encharque na saída e possui ao todo 72 queimadores distribuídos entre as zonas. As zonas de aquecimento são as de 1 a 6 e as de encharque são as de 7 a 12.

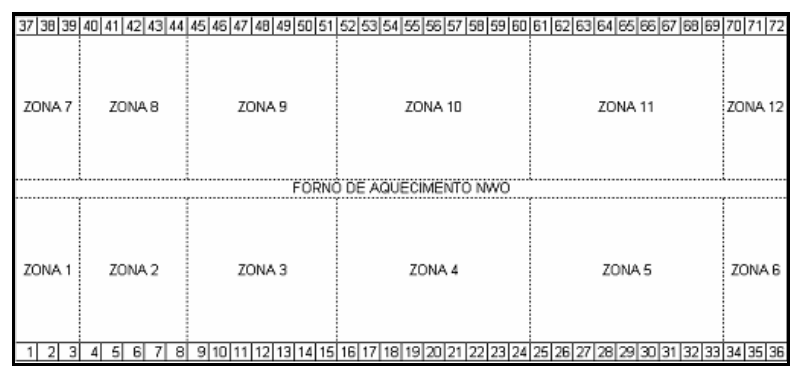

Figura 3 - Zonas imaginárias do Forno

Cada zona possui um termopar para a medição de temperatura que enviado a um controlador digital, que efetua o controle da temperatura comparando este valor medido com um valor de referência preestabelecido. $\mathrm{O}$ erro entre o valor de referência e o medido é convertido em uma saída de 0 a $100 \%$ que é enviada a outro controlador, que determina a porcentagem de queimadores que devem acender proporcionalmente em cada zona de controle. Este controlador comanda também o ciclo dos queimadores para manter a homogeneidade da temperatura na câmara do forno, ciclando alternadamente a proporção de queimadores ligados zona a zona. O forno possui um ajuste do $\mathrm{PCl}$ do gás misto (GM), composto pelo gás de alto forno enriquecido com gás natural, que determina o poder de queima do gás combustível não levando em consideração a sua condensação. O ajuste é feito através do controle da proporção da mistura de GAF com GN. O PCl do GAF varia de 875 a $1.000 \mathrm{Kcal} / \mathrm{Nm}^{3}$ e o $\mathrm{PCl}$ do $\mathrm{GN}$ é $10.000 \mathrm{Kcal} / \mathrm{Nm}^{3}$. É importante ressaltar que devido as placas de orifício que fazem a medição das vazões dos suprimentos do forno serem projetadas para regime de trabalho em temperatura ambiente, as grandezas apresentadas são normalizadas de acordo com a temperatura real do gás e do ar de combustão, portanto a representação é feita utilizando " $\mathrm{Nm}^{3}$ ", lê-se normal metro cúbico.

O "set-point" (SP) ou valor desejado para o $\mathrm{PCl}$ é ajustado pelo operador térmico do forno, que leva em consideração a demanda energética do forno de acordo com o ritmo da produção e a quantidade de GAF disponível. O SP do PCI pode ser ajustado de 0 a $2.781 \mathrm{Kcal} / \mathrm{Nm}^{3}$, mas é limitado pelo controlador digital (CD600) no mínimo em $875 \mathrm{Kcal} / \mathrm{Nm}^{3}$ que é o menor valor atingido pelo GAF. O valor máximo de $2.781 \mathrm{Kcal} / \mathrm{Nm}^{3}$ é dado pelo limite das tubulações, uma vez que a tubulação de GM suporta uma vazão máxima de $27.000 \mathrm{Nm}^{3} / \mathrm{h}$ e a tubulação de GN 3000 $\mathrm{Nm}^{3} / \mathrm{h}$. Para uma mistura totalmente enriquecida, com a tubulação de GM com a vazão máxima de 27.000 $\mathrm{Nm}^{3} / \mathrm{h}$ é necessário uma vazão de $3.000 \mathrm{Nm}^{3} / \mathrm{h}$ de $\mathrm{GN}$ 
e $24.000 \mathrm{Nm}^{3} / \mathrm{h}$ de $\mathrm{GAF}$, que propicia um $\mathrm{PCl}$ de $2.781 \mathrm{Kcal} / \mathrm{Nm}^{3}$.

O forno não possui controle da vazão de ar de combustão, o controle é feito pela pressão do ar que obedece a uma curva calculada e pré-estabelecida, que leva em consideração a composição química do GM. O cálculo desta curva foi um trabalho desenvolvido pela Gerência de Energia com o apoio da Gerência de Manutenção da Laminação Contínua. Tschoepe e Castro (1998) em seus estudos calcularam para cada valor do $\mathrm{PCl}$, de 0 a 1.500 $\mathrm{Kcal} / \mathrm{Nm}^{3}$, um valor para a pressão do ar de combustão ideal para se obter à relação estequiométrica desejada com um excesso de oxigênio na atmosfera do forno em torno de $2 \%$ conforme o Gráfico 1.

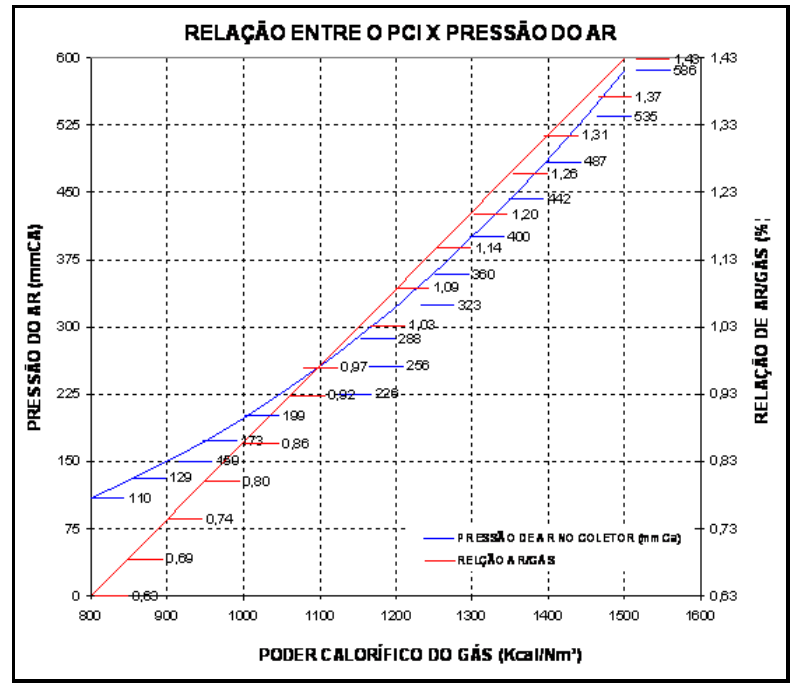

GRÁFICO 1 - PCI X Pressão do Ar

FONTE: Tschoepe; Castro, 1998.

Esta curva foi calculada até $1.500 \mathrm{Kcal} / \mathrm{Nm}^{3}$ porque não havia necessidade de utilização de um valor superior a este quando o projeto foi concebido. Hoje, com as modificações feitas no processo, objetivando o aumento do ritmo de produção, trabalha-se com $\mathrm{PCl}$ superior a este valor. Quando isto acontece não existe controle nesta faixa e o SP de pressão permanece estabilizado. A relação entre Vazão de ar / Vazão de gás / PCI / pressão do forno é mostrada no Gráfico 2 .

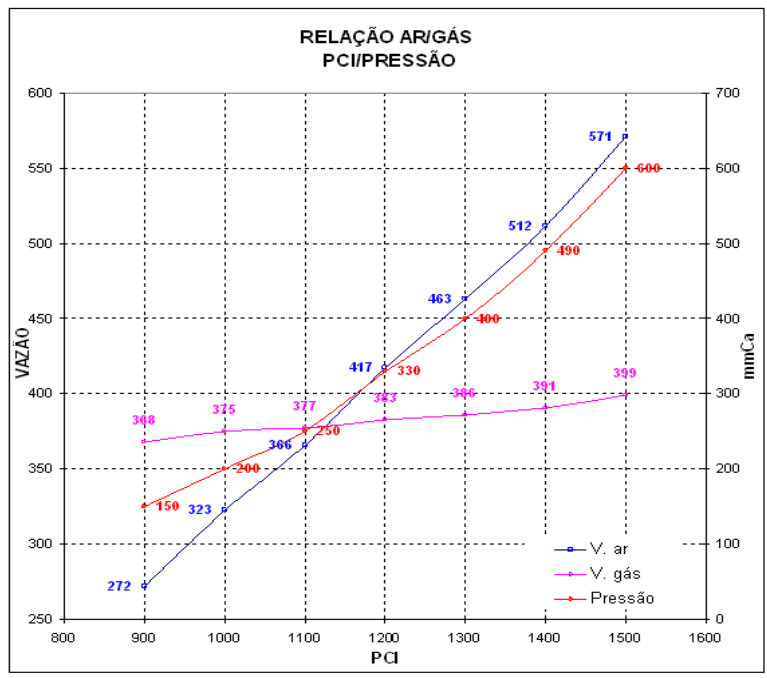

GRÁFICO 2 - Relação entre Vazão de ar / Vazão de gás / $\mathrm{PCl} /$ pressão do forno

FONTE: Tschoepe; Castro, 1998.

O primeiro passo do trabalho foi redimensionar a curva de relação do $\mathrm{PCl}$ com ar de combustão, elaborada pelos autores, para atender uma demanda de $\mathrm{PCl}$ até $2500 \mathrm{Kcal} / \mathrm{Nm} 3$. Apenas utilizaram-se os cálculos já estabelecidos e determinou-se a curva até o valor desejado

A seguir estão exemplificadas as alterações feitas no PLC e no CD600 para automatizar o controle do $\mathrm{PCl}$, ressaltando que foram necessárias alterações apenas na filosofia de controle, sem necessidade de nenhum equipamento ou investimento adicional.

Como o ajuste do $\mathrm{PCl}$ é feito manualmente pelo operador, gera-se um transtorno quanto ao consumo de combustível, uma vez que o ajuste se dá através do controle da proporção da mistura de gás de alto forno próprio enriquecido com gás natural. Quando ocorre uma redução na demanda energética, se não houver intervenção do operador, o controle atua na proporção de queimadores ligados, permanecendo com o mesmo $\mathrm{PCl}$ e conseqüentemente consumindo gás natural. 
Lembrando-se da construção física do forno, conforme Figura 3, o primeiro critério foi verificar se no mínimo uma das doze zonas do forno estava trabalhando com $100 \%$ dos seus queimadores ligados. Estabeleceu-se uma lógica para verificar os bits de comando "ligar queimador" enviados pelo controle de ciclo dos queimadores de cada zona.

Verificou-se também se as temperaturas das zonas estavam acima do SP estabelecido e, para cada zona, obteve-se a configuração mostrada na Figura 4.

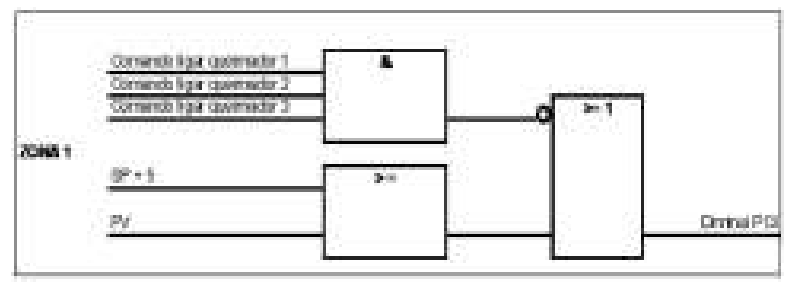

FIGURA 4 - Comando diminui PCI

Nesta situação, para uma parada da produção, o SP do $\mathrm{PCl}$ irá diminuir até uma das zonas atingir o SP desejado com todos os queimadores abertos. Em contrapartida, caso alguma zona esteja com a temperatura abaixo do SP é verificado se todos os queimadores destas zonas estão ligados. Com a zona $100 \%$ aberta e a temperatura abaixo do SP, conforme configuração da figura 5 aumenta-se o $\mathrm{PCl}$ da mistura.

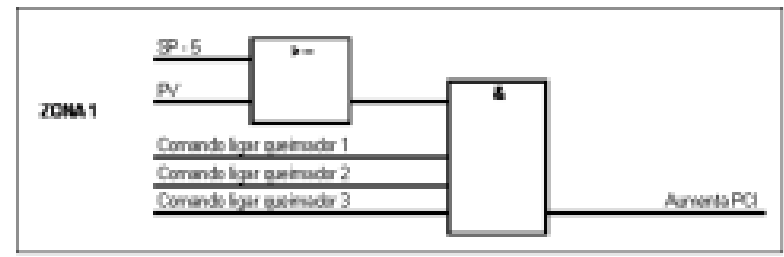

FIGURA 5 - Comando aumentar PCl

Nas figuras 4 e 5 foram apresentadas as configurações apenas da zona 1, para as demais zonas a configuração é idêntica e qualquer uma delas irá enviar o comando para diminuir ou aumentar o $\mathrm{PCl}$ conforme relatado. Os bits que comandam o aumento ou diminuição do $\mathrm{PCl}$ atuam em um bloco seletor que determina o gerador de SP utilizado na planta (Figura $6)$.

e-xacta, Belo Horizonte, v.4, n.1, p. 29-36. (2011) Editora UniBH Disponível em: www.unibh.br/revistas/exacta/

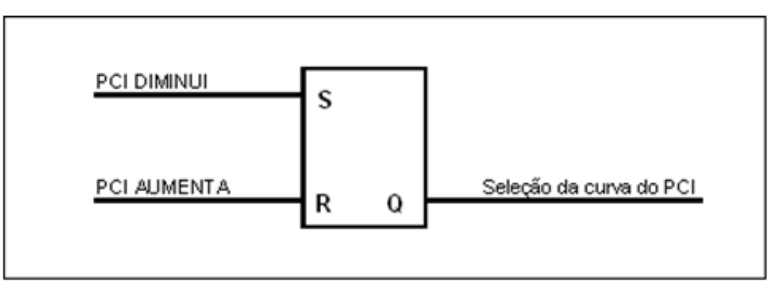

FIGURA 6 - Comando de seleção da curva do PCI

O PLC supervisiona o comportamento do forno, verificando se a temperatura está abaixo ou acima do $\mathrm{SP}$ em todas as zonas e se existe pelo menos uma zona do forno trabalhando com $100 \%$ dos queimadores ligados. Com estas informações, são enviados três comandos para o controlador CD600: comando seleção da curva do $\mathrm{PCl}$ a utilizar, comando diminuir $\mathrm{PCl}$ e comando aumentar $\mathrm{PCl}$.

O bit seleção de $\mathrm{PCl}$ é enviado ao bloco seletor (Figura 7), que irá selecionar qual curva será utilizada. Os outros dois bits, $\mathrm{PCl}$ diminuir e $\mathrm{PCl}$ aumentar, habilitam os blocos geradores de SP que são intertravados entre si com auxilio de um bloco lógico inversor (Figura 8).

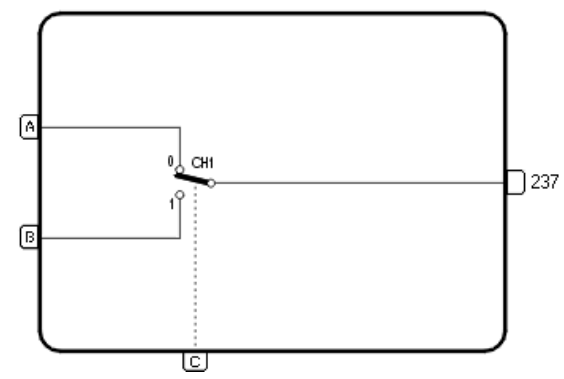

FIGURA 7 - Bloco Seletor

FONTE: Manual controlador CD600, 1994.

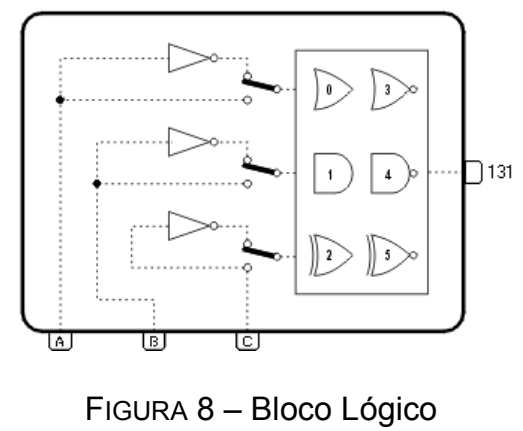

FONTE: Manual controlador CD600, 1994. 
A função do bloco gerador de SP (Figura 9) é gerar um sinal de saída em função do tempo de acordo com a(s) curva(s) armazenada(s) no controlador.

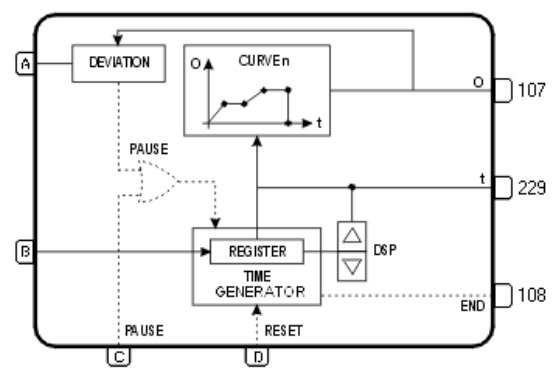

FIGURA 9 - Bloco Gerador de SP

FONTE: Manual controlador CD600, 1994.

O tempo deve ser representado no eixo $X$ e a correspondente saída em Y. Na configuração do bloco é possível selecionar qual o tipo de curva deseja-se utilizar (Figura 10).

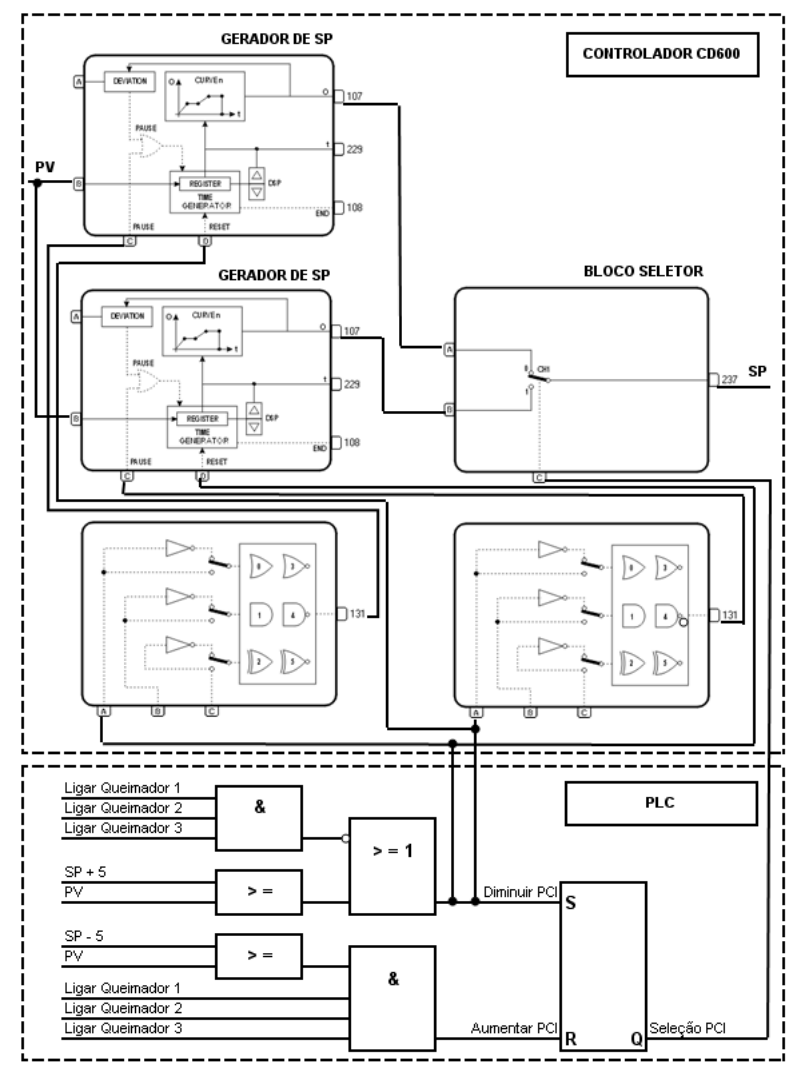

FIGURA 10 - Interligação do PLC com o CD600

FONTE: Manual controlador CD600, 1994.
A saída desta curva é disponível em SP (107) e a saída t (229) informa o tempo decorrido, em porcentagem, do tempo máximo programado no controlador. Quando o tempo é alcançado, a saída END (108) comuta para o nível lógico alto, indicando fim da "batelada". A contagem de tempo pára em $100 \%$ e a variável pára no valor correspondente. Esta situação permanece até que um nível lógico alto na entrada $D$ reset o bloco retornando ao ponto inicial da curva. O retorno da entrada $\mathrm{D}$ ao nível lógico baixo reinicia o processo.

O processo de geração de sinal sempre inicia em um ponto da curva, estabelecido pela entrada B. Se nada é conectado a $\mathrm{B}$ ou $\mathrm{B}=0 \%$, o processo inicia a partir de $t=0 \%$. No caso estudado, na entrada $B$ considerase com o valor da PV como ponto inicial. Este bloco também compara o sinal gerado com a entrada A. Se o desvio for maior que o valor ajustado, a programação de tempo pára até que o desvio seja menor que o ajustado. $\mathrm{O}$ programador de tempo pára em duas situações particulares: quando existir um nível lógico alto na entrada C (PAUSA) ou quando o desvio entre a saída "SP" e a entrada A exceder o valor do limite ajustado.

\section{CoNCLUSÃo}

A nova curva de relação entre o $\mathrm{PCl}$ e a pressão do ar está funcionando perfeitamente após implementação no controlador CD600 e os testes de funcionamento realizados para o controle do $\mathrm{PCl}$ foram totalmente satisfatórios. Para operação em regime contínuo do controle automatizado do $\mathrm{PCl}$ será necessário uma demanda exclusiva de gás de alto forno para que não comprometa o funcionamento de outros equipamentos. Pelos testes efetuados a expectativa é de que seja superada a estimativa de $10 \%$ para redução do consumo de gás natural e uma melhoria considerável da qualidade do material devido a redução do índice de carepa. 


\section{CONSIDERAÇõES FINAIS}

Os resultados finais deste trabalho superaram as expectativas do projeto inicial e, depois de validados os resultados obtidos, caso haja disponibilidade da demanda de gás de alto forno, este projeto poderá ser expandido para todos os fornos da usina que utilizam o gás misto como fonte principal de energia para a combustão.

\section{AgRADECIMENTOS}

Os autores agradecem aos funcionários da Vallourec \& Mannesmann do Brasil, ao Sr. Romildo Rofino pela contribuição fundamental na troca de idéias e ao Sr. Haroldo Furtado, pelos recursos necessários ao projeto.

\section{REFERÊNCIAS}

AGÊNCIA NACIONAL DE ENERGIA ELÉTRICA ANEEL. Banco de Informações de Geração - BIG. 2003. Disponível www.aneel.gov.br/aplicacoes/atlas/pdf/09Gas Natural(2).pdf. Acesso em: 20 mar. 2011.

BRIANE, D.; DOAT, J. Guide technique de la carbonisation: la fabrication du charbon de bois. Aixen-Provence, ÉDISUD, 1985. 180p.

GIL, A. C. Como elaborar projetos de pesquisa. São paulo: Ed. Atlas, 2002. 175p.

JARA, E.R.P. O poder calorífico de algumas madeiras que ocorrem no Brasil. São Paulo: Instituto de Pesquisas Tecnológicas - IPT, 1989.
Manual de instruções do controlador CD600, versão 2. Smar Equipamentos Ind. Ltda - 1994.

PINHEIRO, Paulo César da Costa e VALLE Ramon Molina. Controle de Combustão: Otimização do Excesso de ar. II Congresso de equipamentos e automação da indústria química e petroquímica, Agosto 1995, Rio de Janeiro, RJ.

TSCHOEPE, Bruno Walter e CASTRO, Romildo Rofino. Calculo da Curva de Relação Ar/Gás/PCI/Pressão para o Forno de Combustão da Laminação Contínua da Vallourec \& Mannesmann do Brasil em Setembro de 1998. 